\title{
THE ACTION OF DRUGS ON THE HUMA UTERUS: TOCOGRAPH STUDIES
}

\author{
M. P. EmbreY, M.A., M.D., F.R.C.S., F.R.C.O.G. \\ Nuffield Department of Obstetrics and Gyncecology, Radcliffe Infirmary, Oxford
}

As a natural development of a long-standing interest in uterine contractility several investigations of the effects of drugs on the uterus have been undertaken in the Nuffield Department of Obstetrics and Gynæcology in recent years. These studies form a basis for a review of some recent work of clinical importance concerning the behaviour of the uterus under the influence of various therapeutic agents.

\section{Methods of Recording Uterine Contractility}

All the records of uterine contractility referred to in this paper were obtained by means of the Oxford tocograph. This instrument, which has been fully described elsewhere (Embrey, I955, 1958), provides the facility of both internal and external recording of uterine motility.

In the external method movements of the abdominal wall coincident with uterine contraction are conveyed to a 'Hydroflex' bellows held in the actuating head and transmitted by a sealed hydraulic linkage to a twin 'Hydroflex' bellows, which in turn moves the recording pen. The method is simple: the instrument requires little attention and graphic records of uterine activity, sufficiently accurate for most purposes, can be obtained in pregnancy, during labour and in the early puerperium.

When greater accuracy and exact measurements of intra-uterine pressure are required internal tocography is employed. A small intra-uterine balloon is linked hydraulically to a 'Hydroflex' bellows to form a sealed, precalibrated, easily sterilized and readily available recording unit. The 'Hydroflex' bellows actuates the recording pen of the tocograph. The method used is a modification of the well-proven intra-uterine balloon-mercury manometer method of Bourne and Burn (1927) and Moir (1932a and b). By this means accurate quantitative records can be secured immediately prior to or during labour and also in the puerperium.

The results of laboratory experiment cannot always be translated to clinical practice. Because of species difference in responses there may be disappointment when a new compound, active $\overrightarrow{i n}$ the laboratory, is submitted to clinical trial. Thirty or more years ago, for example, it was thought that ergotoxin and ergotamine were the essential sabstances in crude ergot. Yet, despite their poteny in the laboratory, the alkaloids were disappointeg in practice and much slower in action than crite Ext. Ergot. Liq. (Moir, I932a and b). With the discovery of ergometrine (Dudley and Moir, 1930 rather the reverse obtained. Because the stand@rd animal preparation used for assay was not wholly satisfactory, ergometrine disappointed in the laboratory, yet clinically it was found to be the most powerful oxytocic of all.

In the case of drugs having an alleged influence on uterine contractility, errors of this sort conf avoided by objective tocographic assessment of the agent concerned in the human subject. The $\overline{\text { safthe }}$ of this procedure has been demonstrated in sevie al recent studies.

\section{Ergot Alkaloids}

The first of these studies concerned the fairly recent semi-synthetic ergot alkaloid, dihydioergotamine. This was claimed (Sauter, 1948; Gill and Farrar, I95I) to have no direct oxytacic action, yet was thought to possess strong sympatholytic properties and to be of value in co-ordinate labour. However, Garrett (1995) showed that dihydroergotamine does not mo fffy the effects of either noradrenaline or adrenalime on the parturient uterus, and subsequently Garett and I (Embrey and Garrett, I955) were ableOto demonstrate tocographically the undoubted oxytocic action of the drug (Fig. I).

Similar results were later obtained with hydergine, for which ' anti-sDasmodic' properties had also been claimed. This is a mixture of the dihydro derivatives of ergotoxin, ergocrystine tơd ergocryptine, and it was found (Garrett 迎d Embrey, 1958) that each of these alkaloids and the parent mixture possessed direct oxytocic acti (Fig. I).

In the case of another new synthetic, 'ergotlike' derivative, tochergamine, our experiefce was reversed. Found to exhibit oxytocic actionty 

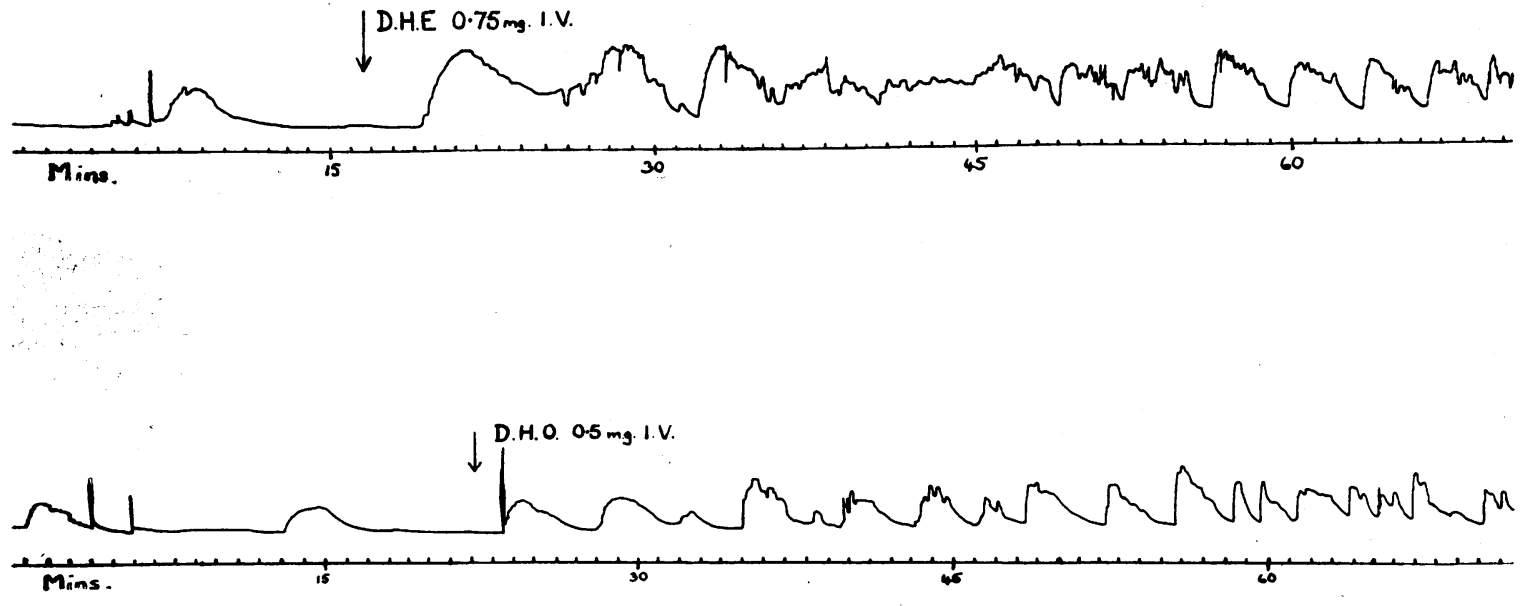

FIG. I.
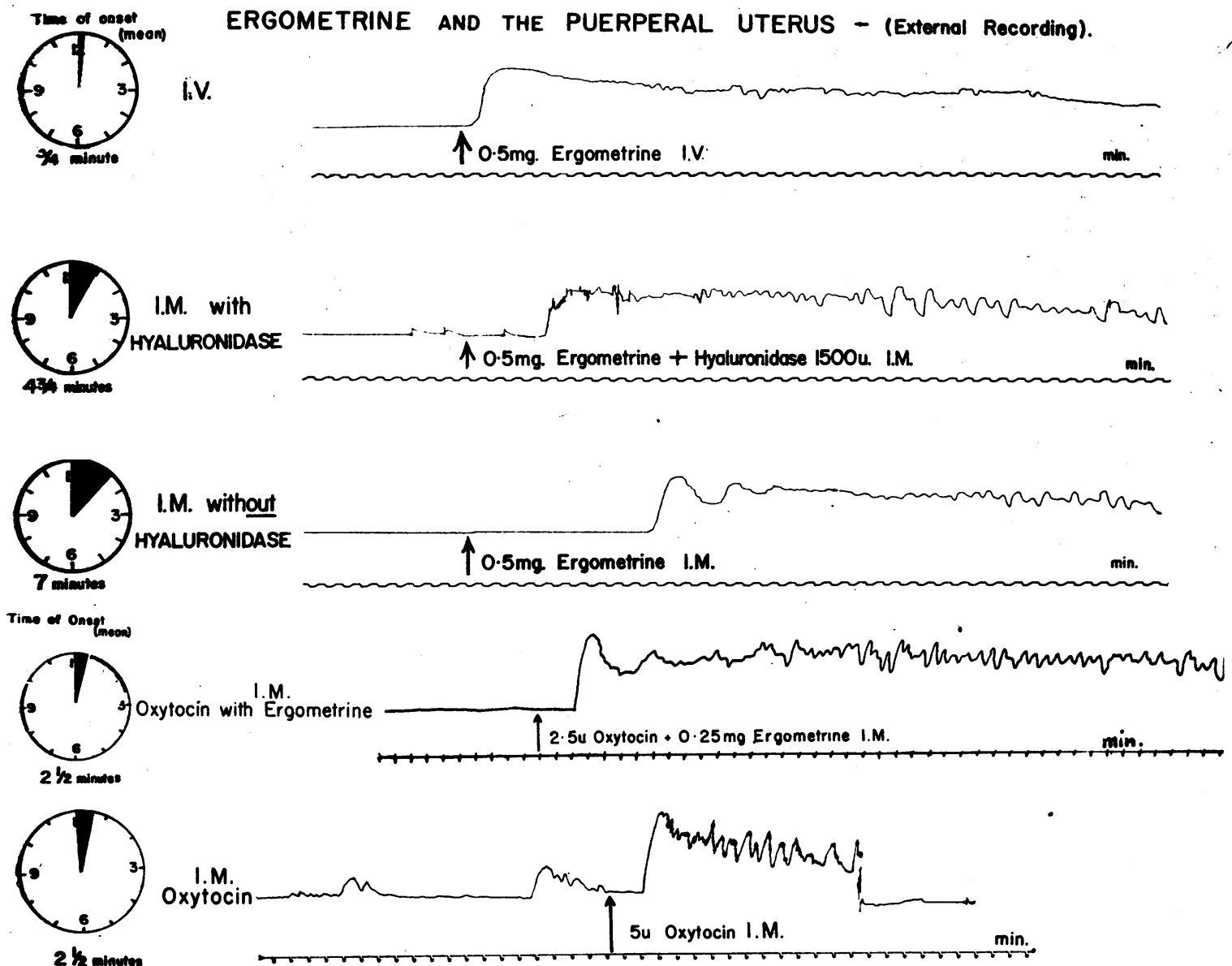

FIG. 2. 
equal to that of ergometrine in experimental animals (Bovet-Nitti, 1952), tochergamine proved quite inactive when tested on the human intact uterus (Garrett and Embrey, 1958).

\section{Speed of Action of Oxytocics}

There has been considerable modification in recent years of the traditional conservative attitude to the management of the third stage of labour. No longer is ergometrine condemned before delivery of the placenta. Nowadays not only is it injected at the first sign of bleeding, but it is commonly given routinely as soon as the head is delivered as a prophylactic against post-partum hæmorrhage.

The quickest effect is obtained by injecting ergometrine intravenously as first advocated by Davis and Boynton (1942). But because midwives are not normally trained to make intravenous injections the use of the simpler intramuscular injection of ergometrine has been recommended (Flew, 1947; Daley, 195I). Some speed and reliability is thereby sacrificed, but greater applicability of the intramuscular method has led to its routine adoption in many units. Elsewhere, in an attempt to improve its speed of action, the addition of hyaluronidase to the intramuscular injection has been advised (Kimbell, 1954).

Some light has been shed on the respective merits of these differing techniques by tocographic experiment. It has been shown (Embrey and Garrett, 1958) that the mean time between injection of ergometrine + hyaluronidase and uterine response is approximately $4 \frac{3}{4} \mathrm{~min}$. This compares favourably with a latent period of about $7 \mathrm{~min}$. for intramuscular ergometrine, but is still far slower than the intravenous injection, which is effective in less than I min. (Fig. 2).

Oxytocin has not been generally favoured-at least, in this country-in the prophylaxis of postpartum hæmorrhage. Chiefly, no doubt, this is because in the past injection of the old pituitary extract was occasionally followed by severe shock, but the pure preparations of oxytocin now available are believed to be much safer. There is also the disadvantage that its spasm-producing property (and, therefore, its hæmostatic action) is inferior to that of ergometrine. But it has the merit of quick action intramuscularly, the mean injection-response interval being approximately $2 \frac{1}{2}$ min. (Embrey, 196r) (Fig. 2). Recently it has been suggested that the two drugs might be combined and now they are available together in a single ampoule for intramuscular injection ('Syntometrine', Sandoz Ltd.) suitable for routine use and providing the rapid action of oxytocin with the more sustained action of ergometrine.
Comparative Effects of Oxytocin and Vasopressin

It is more than 30 years since the posterior? pituitary hormone by a process of chemical frac- $\stackrel{\mathbb{Q}}{\mathcal{Q}}$ tionation (Dudley, I933; Kamm, Aldrich, Grote,. Lowe and Bugbee, 1928) was first persuaded to $\Rightarrow$ yield its two active principles, vasopressin and $\stackrel{\mathcal{S}}{+}$ oxytocin. It has not always been sufficiently을 appreciated, however, that in the commercial pro- ducts, 'Pitressin' and 'Pitocin', available since $\frac{\bar{s}}{\vec{D}}$ then, differentiation is incomplete, so that each $\stackrel{\mathbb{}}{\mathscr{D}}$ contains some $10 \%$ of the other. This might ${ }_{\mathscr{N}}$ explain the doubts that have been raised regarding the specificity of action of the two fractions, the. paradox of the undoubted oxytocic effect of $\vec{\omega}$ 'Pitressin ', at least on occasion, and the conflicting results of animal, in vitro and clinical experimentso (Bourne and Burn, 1928; Robson, 1933; Adair and Haugen, I939; Russell, 1943).

Moir showed in 1944 that, so far as the intact: human uterus was concerned, in early pregnancy vasopressin produced a greater oxytocic response $\vec{\infty}$ than oxytocin, whereas in late pregnancy, labouro and the puerperium the position was reversed and ${ }_{-}$ oxytocin the more powerful drug. Some of this work was repeated by Schild, Fitzpatrick and Nixon in $195 \mathrm{I}$, but with slightly different results. They found that in the first trimester vasopressin $<$ was about equi-active with oxytocin, while in the $\overrightarrow{0}$ second trimester vasopressin was about one and half times more active than oxytocin.

Recently, as a result of the work of Du Vigneaud, Lawler and Popenoe (1953), Du Vigneaud, Ressler, Swan, Roberts, Katsoyannis and Gordon? (1953), Du Vigneaud, Gish and Katsoyannis (1954)융 and Du Vigneaud, Ressler, Swan, Roberts, Katsoyannis aud Gordon (1954), the synthetic pro-ô ducts, oxytocin and vasopressin, have become 3 available and their effect on the intact parturient uterus has been studied. Trials were carried out in pregnancy, labour and the puerperium. In each $\frac{0}{3}$ patient objective records of the effect of equal $\stackrel{3}{-}$ intravenous doses* of the two hormones were obtained, some by internal, some by external means (Embrey, 1958).

The uterine response to an oxytocic, of course, varies with individual susceptibility and (particu- -9 larly) with the physiological activity of the organ, $\frac{D}{0}$ so there is a difficulty about comparing one case with another. But by comparing the 'duration of $N$ action' (i.e. the duration of hypertonus) of oxy- $N$ tocin and vasopressin in arbitrary units in each instance an assay between the two oxytocic drugs.

* The doses used were equal when reckoned unit for unit. The unit of vasopressin refers to its pressor $\frac{C}{\mathscr{C}}$ activity and the unit of oxytocin to its oxytocic activity. The two units of measurement are, in fact, quite unrelated. 
was formulated-with increasing accuracy as the number of cases accumulated.

In the first trimester of pregnancy the oxytocic response to pure vasopressin-especially if the uterus is physiologically active-is a powerful one: this, at least, disposes of the allegation that the oxytocic effect of the old 'Pitressin' is due to contamination with 'Pitocin'. Oxytocin, too, is an active stimulant of contractility at this time. By the method of assay employed the drugs are about equi-active, with vasopressin, if anything, the more powerful oxytocic.

In the middle trimester the effect of vasopressin is still well marked, but the response to oxytocin is appreciably greater. Oxytocin now possesses two or three times the activity of vasopressin.

In the later months of pregnancy, as the behaviour of the uterus gradually changes, the superiority of oxytocin becomes more obvious and as term approaches it is clearly the dominant oxytocic, possessing five to ro times the activity of vasopressin. The effect of vasopressin is now often transient or feeble.

This state of affairs is maintained in parturition when the contractile response of the uterine musculature to oxytocin is spectacular and always far surpasses that of vasopressin; indeed, vasopressin is almost without effect or sometimes merely augments an expected spontaneous contraction. The action of oxytocin in labour is assayed at 10 to 15 times that of vasopressin.

In the puerperium the oxytocic responses evoked by the two hormones are very similar to those seen in labour and again the superiority of oxytocin is overwhelming (Figs. 3 and 4 ).

\section{Relaxin}

Just as the obstetrician during labour may wish to promote or augment uterine contraction and retraction, so, too, it might be advantageous sometimes to be able to inhibit uterine contractility. It would clearly be beneficial, for example, to have
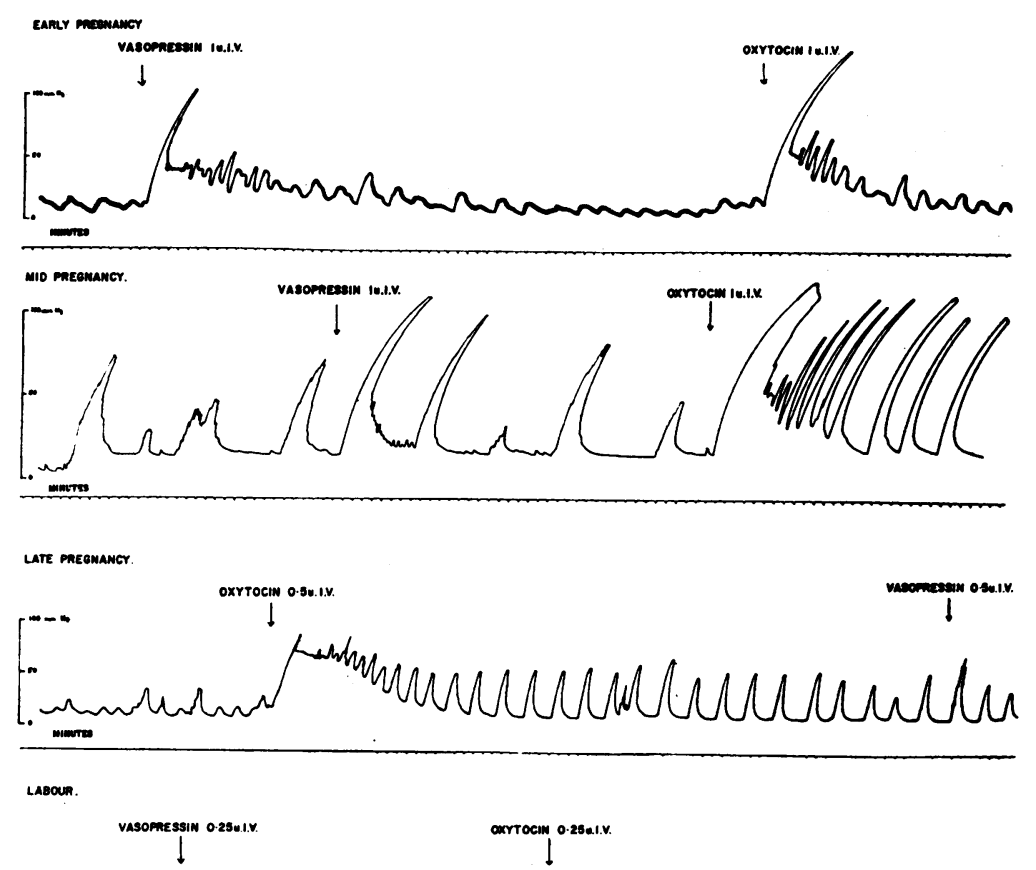

FIG. 3.-The actions of oxytocin and vasopressin.

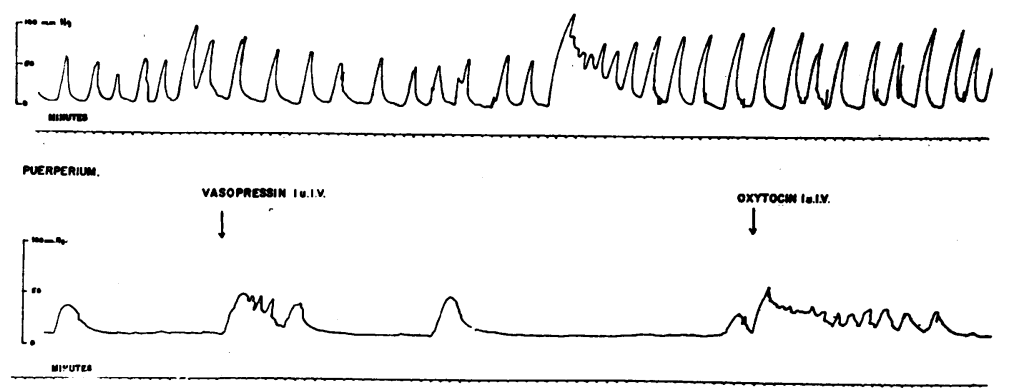


VASOPRESSIN OXYTOCIN

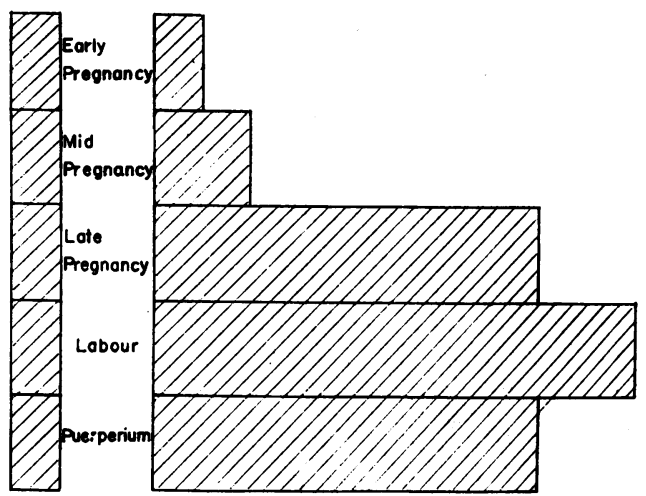

FIG. 4--Relative activities of oxytocin and vasopressin at various stages.

the means of inhibiting the contractions of premature labour.

With the availability of purified preparations from the ovaries of pregnant sows interest has been renewed in relaxin and, a few years ago, there were several claims-based on purely clinical studies - of its ability to suppress premature labour (Abramson and Reid, 1955; Eichner, Waltner, Goodman and Post, 1956; Folsome, Harami, Lavietes and Massell, r956). The claims could not be confirmed tocographically and (whatever other effects it may have) we were able to show (Embrey and Garrett, 1959) that even in very large dosage relaxin has no effect on uterine contractility.

\section{Halothane}

On the other hand, the inhibitory effect of the inhalation anæsthetic halothane on uterine contractility is undoubted. In objective recordings we have shown (Embrey, Garrett and Pryer, 1958) that halothane not only effectively suppresses the contractions of the parturient uterus, but does so rapidly, while-equally important-the effect quickly disappears on withdrawing the anæsthe्cic (Fig. 5). An anæsthetic agent which relaxes the uterus so effectively - without the danger of chloroform or the unpleasant sequelæ of deep ether $\Rightarrow$ is clearly a valuable adjunct to obstetric practice, particularly in circumstances when uterine relasation is essential. Its value can be considerable, 裑or example, when manipulations like version have be performed or when an overdose of oxytocinfor impending tonic contraction threatens uterme rupture. Conversely, the drug is better avoided when relaxation might be dangerous; uterine hæmorrhage may follow its use in vaginal delivgty or Cæsarean section.

\section{Cardiotonic Drugs}

The common clinical experience that patients with cardiac disease on cardiotonic drugs fowequently have a short and easy labour suggested that a careful objective examination of the effect of these drugs on uterine contractility might be profitable. A preliminary (and as yet incomplete) study of one cardiotonic drug was recently undertaken in the department (Embrey and Anselmo, 196r).

The mechanism of action of a cardiotonic drug, such as digitalis, when the heart is in failureasseto increase the force of the cardiac contraction 50 direct effect on the muscle. When the candiac muscle is normal the drug increases the excitability and diminishes the refractory period of the musele (Golman, 1960). With the similarities that exist between the actions of the cardiac and utergine muscle it might be expected that a cardioto ic drug would produce similar effects on the uterine muscle; it would strengthen the contraction and shorten the latent period between contractions.

The three cardiac glycosides present in digitätis lanata each comprise a molecule of sugar 8 n which the drug's solubility and power of cellutar permeation depend) and an aglycone or geain

< FLUOTHANE ANAESTH. >

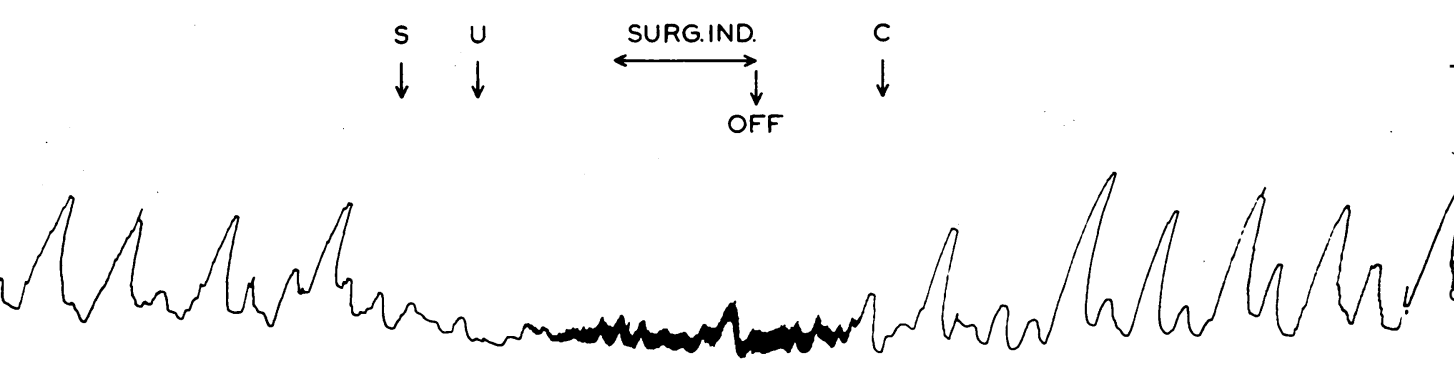

MINS

FIG. 5. 
MRS M.J. I.P. No $25118 / 61$

3rd pay of Puerperium.

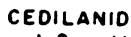

$1.2 \mathrm{mg}$ I $\mathrm{V}$

Sligen increase in uncenewy

EXTERNAL RECORDING
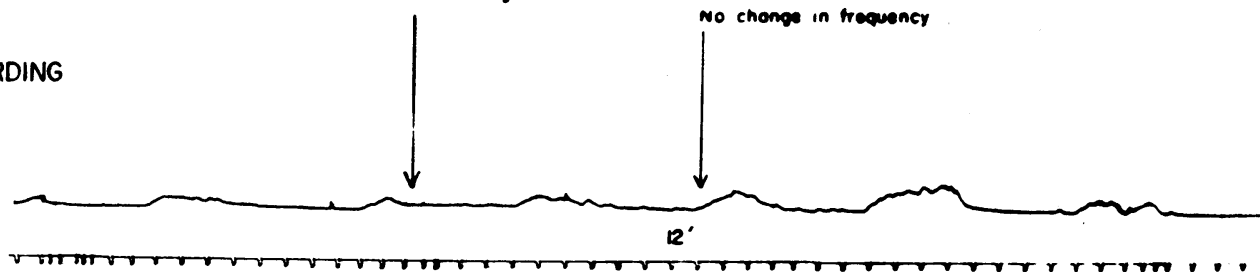

MRS. J.8. I.P. No. $36627 / 61$.

OXYTOCIN INDUCTION.

Segment $310 \mathrm{mU} / \mathrm{min}$.

Frequency 27 per hour.

Intensity $40 \mathrm{mg} . \mathbf{H g}$.

Ut. Activity 1080 units

INTERNAL RECORDING

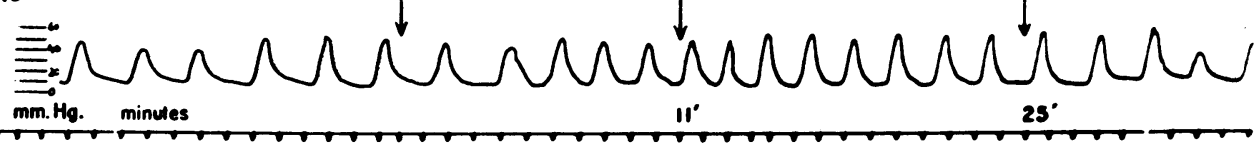

FIG. 6.

composed of a cholanic nucleus with 17 carbon atoms and an unsaturated lactone side chain with four to five carbon atoms. The specific action of the glycoside is that the aglycone acts on the actomysin of the muscle fibril, preventing loss of potassium, and augments the utilization of adenosine triphosphate (ATP), which provides the energy for the reaction which transforms myosin into actomyosin.

Of the cardiac glycosides, digilanid-C was selected for study because it can be used by the intravenous route, acts very rapidly within ro to 20 min., while its maximum effect on the heart is reached in $\mathrm{I}$ to $2 \mathrm{hr}$. The preparation used was the desacetyl derivative of lanatoside-C (" Cedilanid ', Sandoz Ltd.), which consists of the aglycone digoxigenin with three molecules of digitoxose, one molecule of glucose and an acetyl group. The dose for initial digitalization is 1.2 to $1.6 \mathrm{mg}$. by slow intravenous injection.

Records were obtained in 14 cases. In 10 patients tests were made in the early puerperiumfour by external and six by internal means. Four cases were studied by internal tocography in late pregnancy, at the time of induction of labour. The dose of 'Cedilanid' used varied from $0.8 \mathrm{mg}$. to r.6 mg., being increased in the light of experience. All cases had a normal cardiac action. No side- effects were noted after injection. One case had an occasional extra-systole, the irregularity disappearing after one hour. The pulse rate decreased in frequency in all cases by six to ro beats per minute and the blood pressure showed some change in ro cases. It consisted of an increase in systolic pressure from 2 to $8 \mathrm{~mm}$. $\mathrm{Hg}$. No effect was noted in the babies of the four patients studied before delivery.

It can be said at once that, compared with the oxytocic action of the ergot alkaloids or oxytocin, any stimulating effect of 'Cedilanid ' on the uterine activity is slight and of doubtful significance. In the puerperal uterus no constant effect was observed, though some increase in uterine activity was noted in six cases: in two of these the contractions increased in intensity; in four cases there was an appreciable increase in frequency, while in one the frequency was reduced. In the recordings of the activity of the pregnant uterus prior to labour there was an increase in the frequency of contractions in two instances, occurring within the expected time of action of the drug (Fig. 6).

It cannot be considered that these results have any clinical significance, but it would seem worth while to pursue the investigation of the effect of cardiotonic drugs on the uterus.

\section{REFERENCES} Abramson, D., and Reid, D. E. (1955): Use of Relaxin in Treatment of Threatened Premature Labour, f. clin. Endocr.,
15, 206.

Adair, F. L., and Haugen, J. A. (1939): A Study of Suspended Human Uterine Muscle Strips in vitro, Amer. F. Obstet. Gynec., 37, 753 
Bourne, A. W., and Burn, J. H. (1927): The Dosage and Action of Pituitary Extract and of the Ergot Alkaloids onathe Uterus in Labour with a note on the Action of Adrenaline, F. Obstet. Gynac. Brit. Emp., 34, 249.

,-- (1928): The Action of Oxytocin and Vasopressin on the Uterus in Labour, Lancet, ii, 694.

Bovet-NitTI, F. (1952): Ricerche sulle proprieta oxitocicche nella serie dell, ergotammina. Aziome farmacoloqica della N-(2-tetralil), N-metil-N-isopropanol alanin ammide (833.r.S.) e della N, N dietil-N (2 tetralil) glicinamrgide

(62 I.I.S.), R.c. ist Sup. Saint, 15, 953.
DALEY, D. (195 I): The Use of Intramuscular Ergometrine at the end of the Second Stage of Labour, F. Obstet. Gyegac. Brit. Emp., 58, 388.

Davis, M. E., and Boynton, M. W. (1942): The Use of Ergonovine in the Placental Stage of Labour, Amer. F. Obstef Gynec., 43, 775 .

Dudley, H. W. (1923): On the Active Principles of the Pituitary Gland, f. Pharmacol. exp. Ther., 21, ro3. , and MoIr, J. C. (1935): The Substance Responsible for the Traditional Clinical Effect of Ergot, Brit. med\$ $\mathcal{G}$., i, 520 .

Du Vigneaud, V., Lawler, H. C., and Popenoe, E. A. (1953): Enzymatic Cleavage of Glycinamide from Vasopręsin and the Proposed Structure for this Pressor Anti-diuretic Hormone of the Posterior Pituitary, F. Amer. chem. 75, 4880 .

-, Ressler, C., Swan, J. M., Roberts, C. W., Katsoyannis, P. G., and Gordon, S. (i953): The Synthesis of Octapeptide Amide with the Hormonal Activity of Oxytocin, Ibid., 75, 4879.

- Gish, D. K., and Katsoyannis, P. G. (1954): A Synthetic Preparation Possessing Biological Prope Associated with Arginine Vasopressin, Ibid., 76, 475 I.

-, Ressler, C., Swan, J. M., Roberts, C. W., and Katsoyannis, P. G. (1954): The Synthesis of Oxytocin,

Eichner, E., Waltner, C., Goodman, M., and Post, S. (1956): Relaxin, the Third Ovarian Hormone: Its Exp mental Use in Women, Amer. F. Obstet. Gynec., 71, 1035.

Embrey, M. P. (1955): A New Multichannel External Tocograph, f. Obstet. Gynac: Brit. Emp., 62, I.

- (1958): A Simplified Internal Tocograph, Ibid., 65, 529.

(1959): A Criterion of Oxytocic Activity, Ibid., 66, 871 .

(I96I): Simultaneous Intramuscular Injection of Oxytocin and Ergometrine: A Tocographic Study, Brit. med.尹., i, 1737 , and Anselmo, J. (196I): Unpublished data.

, and GarretT, W. J. (1955): A Study of the Effect of Dihydroergotamine on the Intact Human Uterus, Pa Oxytocic Properties, F. Obstet. Gynac. Brit. Emp., 62, 150.

- - (1958): Ergometrine with Hyaluronidase: Speed of Action, Brit. med. F., ii, 138. Emp., 66, 594. The Effect of Relaxin on the Contractility of the Human Pregnant Uterus, F. Obstet. Gynag Rit. Lancet, ii, ro93.

FLEw, J. D. S. (I947): Discussion on the Management of the Normal Third Stage of Labour and Therein, Proc. roy. Soc. Med., 40, 370.

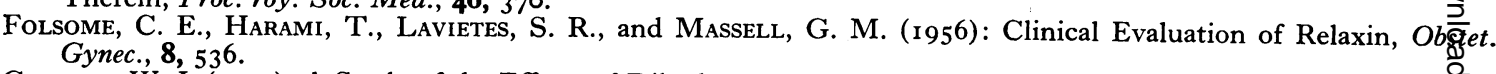

GARRET, W. J. (I955): A Study of the Effects of Dihydroergotamine on the Intact Human Uterus, Part I, Sympa每olytic Properties, F. Obstet. Gynac. Brit. Emp., 62, 145. , and EMBrEy, M. P. (I955): The Effect of the Hydrogenated Ergotoxin Group Alkaloids on the Intact Hugian
Uterus, Ibid., 62, 523.

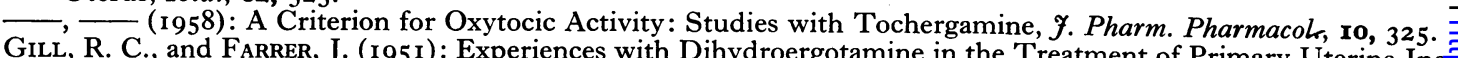
f. Obstet. Gynac. Brit. Emp., 58, 79.

Golman, A. (1960): 'Pharmacology and Therapeutics', fourth edition. London: Lea-Febinger.

Kamm, O., Aldrich, T. B., Grote, I. W., Rowe, L. W., and Bugbee, E. P. (1 928): The Active Principles of the Posterior Lobe of the Pituitary Gland: (1) The Demonstration of the Presence of Two Active Principles; (2) The Separa每on of the Two Principles and their Concentration in the Form of Potent Solid Preparations, F. Amer. chem. SHoc. 50, 573 .

KIMBELL, N. (1954): Intramuscular Ergometrine and Hyaluronidase in the Prevention of Postpartum Hæmorrh Brit. med. $\mathcal{F}$., ii, I30.

MoIr, J. C. (1932a): Clinical Comparison of Ergotoxin and Ergotamine, Ibid., i, ro22.

- (1932b): The Action of Ergot Preparations on the Puerperal Uterus, Ibid., i, I I 9. (1944): The Effect
Brit. Emp., 51, I 8 I. Robson, J. M. (I933): The Reactivity and Activity of the Rabbit's Uterus during Pregnancy, Parturition and fhe $^{2}$
Puerperium, $\mathcal{F}$. Physiol., 78, 309.

Russell, C. S. (I943): The Response of Isolated Muscle Strips from the Upper and Lower Segments of the Hum N Full-time Pregnant Uterus to Pitressin and Pitocin, F. Obstet. Gynac. Brit. Emp., 50, 287.

SAUTER, H. (1948): Verwendung von dihydroergotamin (D.H.E.45) in der geburtshilse, Schweiz. med. Wschr., 78,

Schild, H. O., FitzPatrick, R. J., and Nixon, W. C. W. (I95 I). Activity of the ischweiz. med. Wschr., 78, 475. Lancet, i, 250. 